Available online at http://docs.lib.purdue.edu/jate

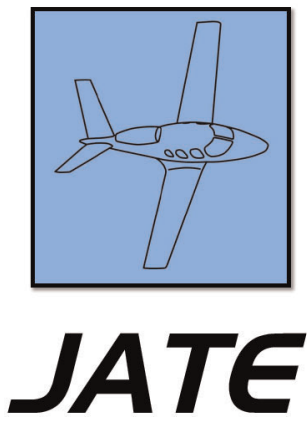

Journal of Aviation Technology and Engineering 9:1 (2020) 2-15

\title{
Empirical Analysis of Trends in Runway Incursions in the United States from 2001 to 2017
}

\author{
David C. Ison \\ Northcentral University
}

\begin{abstract}
Runway incursions, events in which an aircraft, vehicle, or person is located on a runway surface without authorization, continue to be a constant threat to aviation safety. Previously identified on the "Most Wanted" list of aviation safety issues by the National Transportation Safety Board, the Federal Aviation Administration (FAA) has spent significant amounts of money and effort to address runway incursions. Little empirical evidence has been collected on the effectiveness of such efforts. Moreover, the data that are available provide a confusing landscape of contradicting findings. Some FAA publications claim that runway incursions are decreasing while the evidence provided in such documents support the contrary. News headlines tout decreases in runway incursions while briefly stating that they are increasing in recent years. The purpose of this quantitative causal-comparative and correlational study was to provide an improved understanding of trends in runway incursions based on statistical analysis rather than on generalizations. The findings of this study indicated that from 2001 to 2017 runway incursions appear to have a strong, positive correlation with ascending years, i.e., are increasing over time ( $\rho=0.995, p<0.001)$. Each type of incursion severity category (A, B, C, and D) is further analyzed. Also, analysis for the last five and ten years was conducted to focus on more recent trends. Suggestions for future research are also provided.
\end{abstract}

Keywords: aviation, safety, airports, runway incursion, quantitative

\section{Introduction}

Runway incursions, events in which something (e.g., an aircraft, vehicle, or pedestrian) erroneously occupies a runway, are considered an extremely serious hazard to aviation. One of the worst aviation accidents was a result of a runway incursion. Because of an aircraft operating on the runway in Tenerife, Canary Islands, contrary to air traffic control expectations, two Boeing 747s collided, claiming 583 lives (National Transportation Safety Board [NTSB], 2007). The potential for fatalities among runway incursions cannot be underestimated, especially considering increasing global air traffic as well as the utilization of supersized aircraft such as the Airbus A-380 with a seating capacity of over 600 passengers (Federal Aviation Administration [FAA], 2017a; Mutzabaugh, 2015). For several years, the NTSB has placed runway safety improvements on its list of "Most Wanted Transportation Safety Improvements" calling for the FAA to take significant measures to decrease rates of incursions (NTSB, n.d.). Clearly, the tracking of runway incursion incidence is paramount for scrutinizing system safety and identifying problematic trends. Accordingly, the FAA has 
implemented mandatory reporting of runway incursion events and stores the resultant data within its Runway Incursion Database (RWS) (FAA, 2017b).

To address multi-agency concerns over runway incursions, the FAA has invested in a variety of safety enhancements, including Airport Surface Detection Equipment-Model X (ASDE-X) and Runway Status Lights (RWSL). The former is a system that improves air traffic control oversight and monitoring of aircraft and vehicle movements on the ground while the latter provides visual indications to pilots and drivers about the occupancy status of runways and clearance to enter such areas (FAA, 2007; Office of the Inspector General-Department of Transportation [OIG], 2018).

Of course, if these investments yield significant improvements in safety, it can be said that the benefits outweighed the costs. When dealing with saving lives, even a slight improvement in safety can be considered a success. However, the reality is that the success of runway safety improvements, specifically that of RWSL, has not been empirically analyzed. The FAA repeatedly reports "success" in its runway incursion rates displayed in annual performance and accountability reports, yet the treatment of the data is limited to displaying graphs, which include misleading visual indicators marking trends in the data (FAA, 2014, 2015a, 2016, 2017a). News articles provide more confusion by reporting that while runway incursions in the USA have declined since the 1990s, incursions are actually on the rise since 2013 (Flight Safety Foundation [FSF], 2017). Unfortunately, no statistical analysis of runway incursion rates has been conducted to identify what trends in rates exist and if differences beyond "eyeballing" of data are significant (Morrison \& Winston, 2008; Schönefeld \& Möller, 2012).

Considering these issues, it appears necessary to evaluate the efficacy of FAA investments in runway incursion prevention. The question that remains is: what is the actual trend in runway incursions in the USA? Currently, the problem is that there have been mixed messages about runway incursion rate changes. Moreover, there has been no statistical analysis of the available data. Evaluations of incursion trends can provide insight into the effectiveness of programs such as ASDE-X and RWSL. They can also help evaluate the return on investment of over $\$ 1$ billion of tax-payer dollars and appraise the allocation of safety improvement funds to the best possible technologies, procedures, and education strategies (Schönefeld \& Möller, 2012; Van Eekeren, Wright, \& Čokorilo, 2018).

\section{Literature Review}

\section{Defining runway incursions}

A runway incursion is currently defined by the FAA, as adopted from the International Civil Aviation Organization
(ICAO), as "any occurrence at an aerodrome involving the incorrect presence of an aircraft, vehicle or person on the protected area of a surface designated for the landing and takeoff of aircraft" (FAA, 2008, p. 37). Incursions are categorized by severity to reflect the level of danger to airport operations. Category A and B events are highlighted as "serious incursions" by the FAA (2017a, p. 43) and involve the highest risk for accident occurrence. The formal definitions for each category are:

- Category A: a serious incident in which a collision was narrowly avoided.

- Category B: an incident in which separation decreases and there is a significant potential for collision, which may result in a time-critical corrective/evasive response to avoid a collision.

- Category C: an incident characterized by ample time and/or distance to avoid a collision.

- Category D: incident that meets the definition of runway incursion such as the incorrect presence of a single vehicle/person/aircraft on the protected area of a surface designated for the landing and takeoff of aircraft but with no immediate safety consequences (FAA, 2017a).

It is important to note that the FAA changed its definition of runway incursions, adopting the ICAO standards outlined above, effective 2008. What the FAA previously classified as category $\mathrm{C}$ and D incidents now fall within category $\mathrm{C}$. The current category $\mathrm{D}$ did not technically exist in the FAA nomenclature before 2008. See Figure 1 for a comparison of pre-2008 and current definitions.

Because of the definition changes, there was a spike in category $\mathrm{C}$ and $\mathrm{D}$ events in 2008. While these changes in classifications made analyzing data before and after the revision more complicated, the severity categories (A and B) remained analogous. Figure 2 shows the impact of the adoption of the ICAO definition for incursions had on total numbers of reported events. Of course, this caused total runway incursion numbers and associated graphics to indicate a dramatic rise in incursions. Thus, caution in making comparisons across all categories, especially category D, before and after the definition change is necessary (FAA, 2008, 2009, 2010; United States Government Accountability Office, 2008).

\section{Previous research on runway incursions}

Research on runway incursions has taken a variety of forms but generally tends to concentrate on the seriousness of the threat they present to aviation as well as mitigation strategies. Mrazova (2014) highlighted the significant progress that has been made worldwide to combat incursions but cautioned that stakeholders must "be careful and concentrate...on the effort to keep as low as possible the numbers of incidents" (p. 71). The author described the 


\begin{tabular}{|c|c|c|c|}
\hline \multicolumn{2}{|c|}{ FAA Definition Prior to FY 2008} & \multicolumn{2}{|c|}{ Current FAA Definition } \\
\hline Class & Description & Class & Description \\
\hline \multirow[b]{2}{*}{ A } & \multirow{2}{*}{$\begin{array}{l}\text { Separation decreases and } \\
\text { participants take extreme action } \\
\text { to narrowly avoid a collision, or } \\
\text { the event results in a collision. }\end{array}$} & Accident & $\begin{array}{l}\text { Refer to ICAO Annex } 13 \\
\text { definition of an accident. }\end{array}$ \\
\hline & & A & $\begin{array}{l}\text { A serious incident in which } \\
\text { a collision was narrowly } \\
\text { avoided }\end{array}$ \\
\hline B & $\begin{array}{l}\text { Separation decreases and there } \\
\text { is a significant potential for a } \\
\text { collision. }\end{array}$ & B & $\begin{array}{l}\text { An incident in which } \\
\text { separation decreases and } \\
\text { there is a significant potential } \\
\text { for collision, which may result } \\
\text { in a time critical corrective/ } \\
\text { evasive response to avoid a } \\
\text { collision. }\end{array}$ \\
\hline C & $\begin{array}{l}\text { Separation decreases, but } \\
\text { there is ample time and } \\
\text { distance to avoid a potential } \\
\text { collision. }\end{array}$ & C & $\begin{array}{l}\text { An incident characterized by } \\
\text { ample time and/or distance } \\
\text { to avoid a collision. }\end{array}$ \\
\hline D & $\begin{array}{l}\text { Little or no chance of a collision } \\
\text { but meets the definition of a } \\
\text { runway incursion. }\end{array}$ & & \\
\hline \multirow[t]{2}{*}{$\begin{array}{l}\text { Other } \\
\text { Surface } \\
\text { Incidents }\end{array}$} & \multirow[t]{2}{*}{$\begin{array}{l}\text { An event during which } \\
\text { unauthorized or unapproved } \\
\text { movement occurs within } \\
\text { the movement area or an } \\
\text { occurrence in the movement } \\
\text { area associated with the } \\
\text { operation of an aircraft that } \\
\text { affects or could affect the safety } \\
\text { of flight. (This subset includes } \\
\text { only non-conflict events). }\end{array}$} & D & $\begin{array}{l}\text { Incident that meets the } \\
\text { definition of runway } \\
\text { incursion such as incorrect } \\
\text { presence of a single vehicle/ } \\
\text { person/aircraft on the } \\
\text { protected area of a surface } \\
\text { designated for the landing } \\
\text { and takeoff of aircraft but } \\
\text { with no immediate safety } \\
\text { consequences. }\end{array}$ \\
\hline & & $\begin{array}{c}\text { Not } \\
\text { Defined }\end{array}$ & $\begin{array}{l}\text { FAA non-conflict surface } \\
\text { incidents include more than } \\
\text { just ICAO class "D" events. }\end{array}$ \\
\hline ID & $\begin{array}{l}\text { Insufficient Data-inconclusive or } \\
\text { conflicting evidence precludes } \\
\text { severity assessment. }\end{array}$ & E & $\begin{array}{l}\text { Insufficient information } \\
\text { inconclusive or conflicting } \\
\text { evidence precludes severity } \\
\text { assessment. }\end{array}$ \\
\hline
\end{tabular}

Figure 1. Comparison of pre-2008 and current FAA definitions of runway incursions. From FAA (2008).

different parties that were found to be at fault in incursion events, namely air traffic control, flight-crew/pilots, and drivers (i.e., vehicle). Pilot deviations have historically been the largest source of incursions. In particular, general aviation pilots were the overwhelming cause of most incursions. Additional threats to runway safety that were described included pedestrians and wildlife.

Schönefeld and Möller (2012) reviewed runway incursion avoidance and alerting systems in detail. The authors noted incursion trends at the time of publication and forecasted traffic growth incursions were likely to increase. The study indicated that runway incursions are not a problem localized to the USA, as European airports such as Zurich and London Heathrow report a large number of events annually. As incursions are due primarily to human error, mitigation is best approached by data fusion of sensors, maps, tracks, and movement models at individual airports to help operations stakeholders to avoid mistakes. Based on simulation, the study highlighted that there is the potential of up to an $80 \%$ reduction in runway incursions 


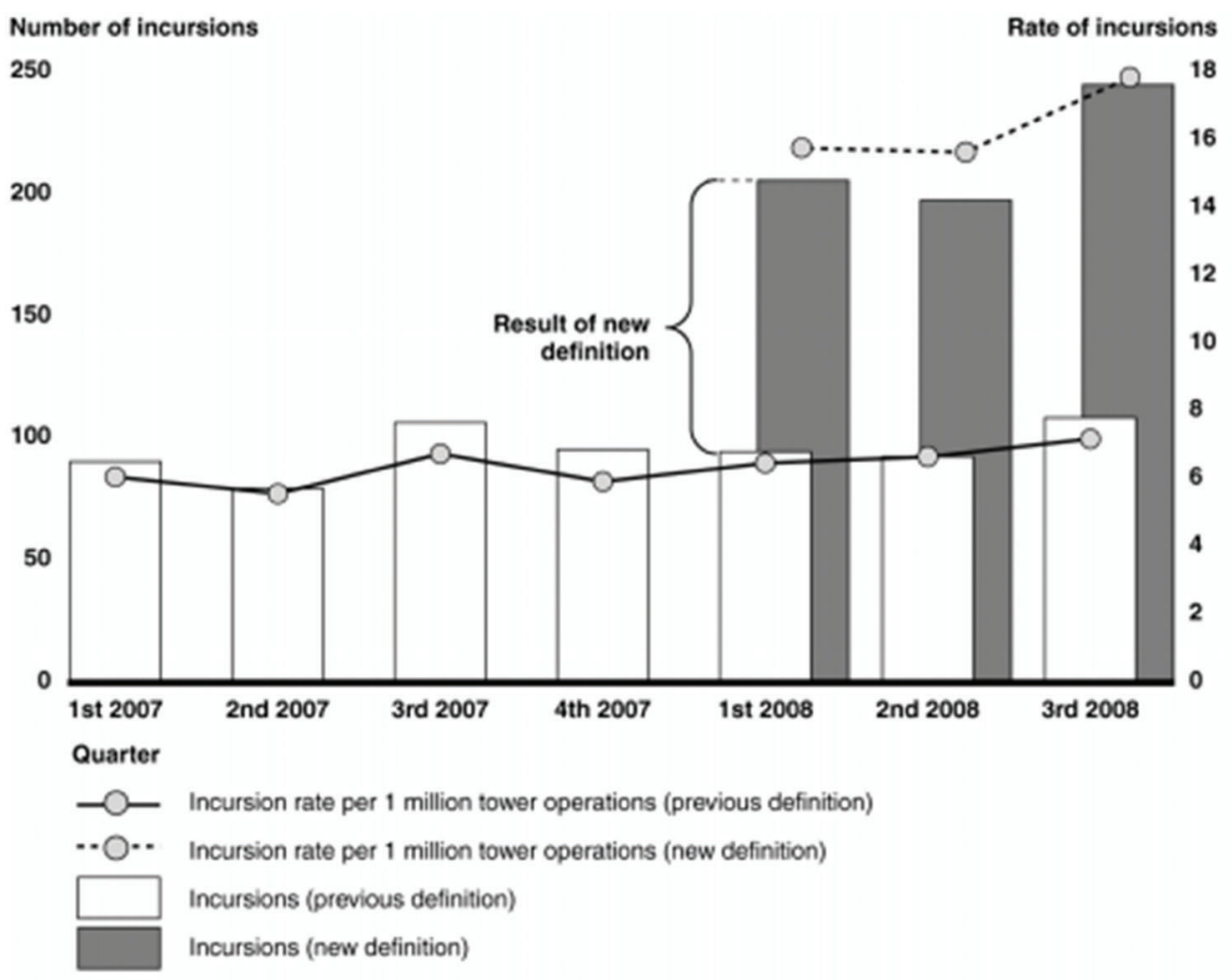

Figure 2. Incursions, by quarter, during fiscal year 2007 and fiscal year 2008. From United States Government Accountability Office (2008).

when mitigation technologies are correctly installed and used. It was noted that the introduction of Final Approach Runway Occupancy Signal (FAROS) and RWSL reduced incursions at Dallas-Ft. Worth International Airport by as much as $70 \%$ (Schönefeld \& Möller, 2012).

According to Schönefeld and Möller (2012), runway incursion avoidance relies on four essential elements. The pilot-centric "own ship position awareness" and "route awareness" (Schönefeld \& Möller, 2012, p. 35) are critical, as pilots must maintain situational awareness of where they are and where they are traveling on the airport surface. Also, "route deviation detection" (Schönefeld \& Möller, 2012 , p. 35) is needed to determine when pilots deviate from the expected surface route. Lastly, "runway activity status" (Schönefeld \& Möller, 2012, p. 35) is necessary to detect runway occupancy or impending occupancy for both pilots and controllers. Proper incursion prevention system functioning is reliant on a variety of technologies and programming algorithms, all of which are potentially very expensive and complex (Schönefeld \& Möller, 2012).

Schönefeld and Möller (2012) detailed the theoretical potential for increased safety through prevention systems. However, there was no statistical analysis of existing data. Moreover, "the installation of signals is a costly process" requiring the installation of "kilometers of cables" (Schönefeld \& Möller, 2012, p. 37) in addition to component costs. The maintenance costs of such systems are also high because they must be kept in perfect working in order to be effective.
In one of the only studies available in current literature utilizing an empirical analysis of runway incursion data, Green (2013) examined characteristics of and rates of incursions. It was determined that from 2001 to 2012, only category $\mathrm{C}$ and $\mathrm{D}$ incursions increased by a statistically significant amount $(p \leq 0.10)$, while there was no such significance in changes in category A and B events. The author was not aware of or did not disclose the possible limitation of the change in the definition of runway incursions that became effective in 2008 as a potential influence on the outcomes of this analysis. Using a coding schema for category A (with a collision) incursions (coded "5") through category D events (coded "1"), a linear robust structure model was developed. The projected slope for category $\mathrm{D}$ was positive and steep, indicating an increase in such events. The same was noted for category $\mathrm{C}$, although with a positive slope that was less severe. The slopes for categories A with a collision, A, and B all had slight negative slopes.

\section{Confusing data on runway incursion trends}

A common trait within the available literature is that there is no consensus on trends in runway incursions and the actual impact that runway incursion mitigation improvements have had on system safety. In August 2017, the FSF published an article titled "Serious Runway Incursions Down at U.S. Airports." The document highlighted that "the number of serious runway incursions at 
U.S. airports has declined dramatically over the past nearly 20 years" (FSF, 2017, para. 1). Nevertheless, in reference to serious runway incursions, the sentence finishes "but has been trending higher since 2013, according to the Federal Aviation Administration (FAA) statistics" (FSF, 2017, para. 1). The article highlighted the fact that RWSL has been installed at eleven large U.S. airports and installations at nine more are in progress, including New York JFK International and Chicago O'Hare airports, implying that these systems have been successful in reducing incursions (FSF, 2017).

Existing research on runway incursions provides a mixed message about the assumption that runway incursions have decreased. Models calculated by Green (2013) indicated a positive slope (increase) in runway incursions from 2001 to 2012. Mrazova (2014) stated that there was a $21 \%$ reduction in incursions between 2011 and 2012. Yet the author stated, based upon increasing traffic levels, it could be expected that this trend would reverse.

Data from the FAA further add to the confusion about actual trends in runway incursions. In both the 2015 and 2016 Performance and Accountability Reports, the FAA (2016) provided diagrams of runway incursion rates which are perplexing (see Figures 3 and 4). As can be seen in the graphical depictions from the report, there is a large down arrow indicating a decrease in the rate of serious runway incursions. However, the trend for actual incursions is not in agreement with the claim of reduced incidence. Contrarily, the difference between actual rates from 2010 (0.117 per million operations [PMO]) to 2015 (0.302 PMO) shows a $158 \%$ increase in the rate. There was a $160 \%$ increase in the rate when comparing 2011 (0.138 PMO) versus 2016 (0.360 PMO). In the 2016 report, the FAA claimed that it had "made significant progress in improving

\section{SERIOUS RUNWAY INCURSIONS RATE}

Per million operations

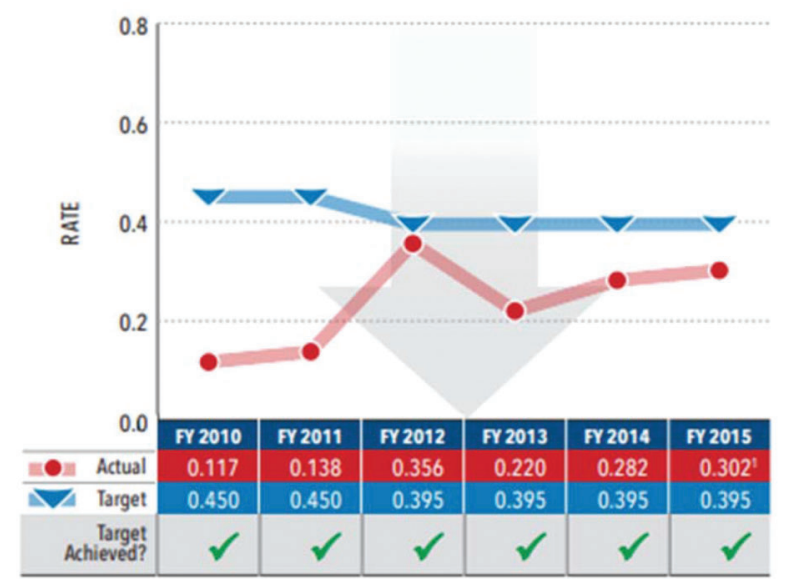

Figure 3. Serious runway incursion rate graphic published in 2015. From FAA (2015a).

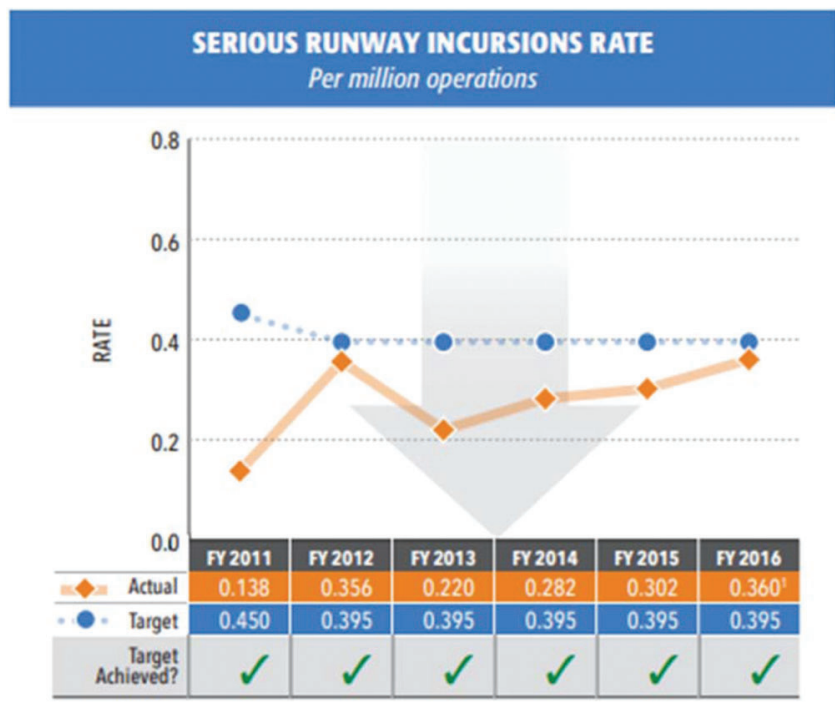

Figure 4. Serious runway incursion rate graphic published in 2016. From FAA (2016). 
runway safety at U.S. airports over the past 15 years" and that the FAA had been successful because the actual rate was below its "target" measure (FAA, 2015a, 2016).

In the 2017 FAA Performance and Accountability Report, it was indicated that runway incursion rates decreased by 65\% from 2016 (see Figure 5) (FAA, 2017a). When comparing 2011 to 2017 , there was a $5.8 \%$ reduction in incursion rates. In contrast, when comparing 2010 to 2017 , incursions had increased by $11 \%$. Further, the data in the report were preliminary for 2017 . From more current data, the actual incursion rate for 2017 was 0.160 PMO, indicating a 16\% increase from 2011 and up 36\% from 2010 . When comparing 2016 and 2017 data, there was a 55\% reduction (FAA, 2016, 2017a, 2017b, n.d.).

In a separate document, the FAA stated that it had completed its goal of a $25 \%$ reduction in the number of serious runway incursions as the actual reduction in incursion numbers was $44 \%$. The published graphic can be seen in Figure 6. While there is no doubt that, based on the provided data, the numbers of dangerous occurrences are trending downwards, though caution is necessary when looking at counts as they do not reflect potential influences that fluctuations in traffic and other potential confounding variables may have on these data. Figure 7 shows the airport operations volume, which was down $13 \%$ from 2008 to 2014 which likely had an impact on counts of incursions.

Complicating the claim of runway incursion reduction is that while serious incursions were down for 2017 , the total number of incursions continues to rise since the incursion definition change in 2008, as can be seen in Figure 8. Additional figures provided by the FAA indicated that there is a trend of increasing numbers of runway incursions (see Figure 9). The "achievement" of annual FAA targets is also misleading as, if examined at the monthly levels in data from 2014, there are several instances that indicate an exceedance of performance limits for incursion rates

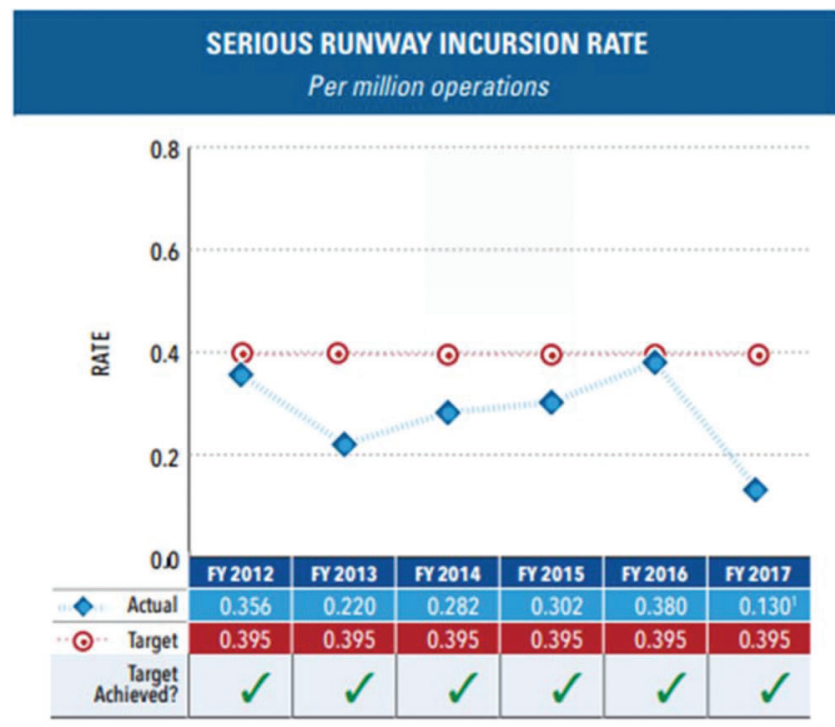

Figure 5. Serious runway incursion rate graphic published in 2017. From FAA (2017a).

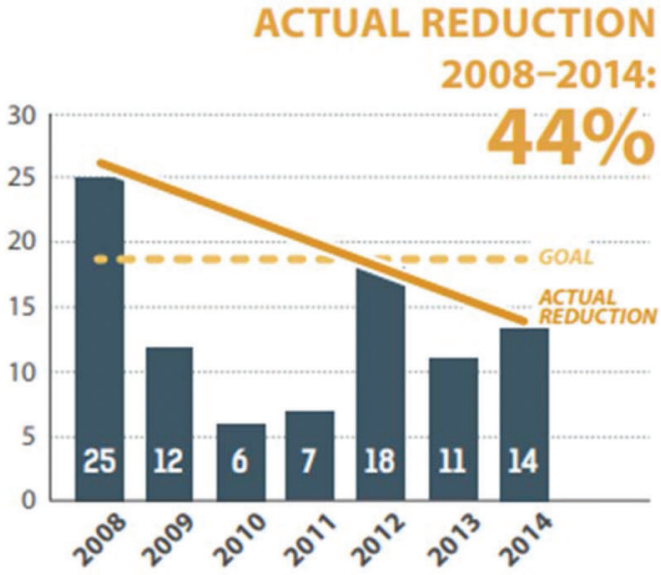

Figure 6. Serious runway incursion rate graphic published in 2017. From FAA (2017a). 


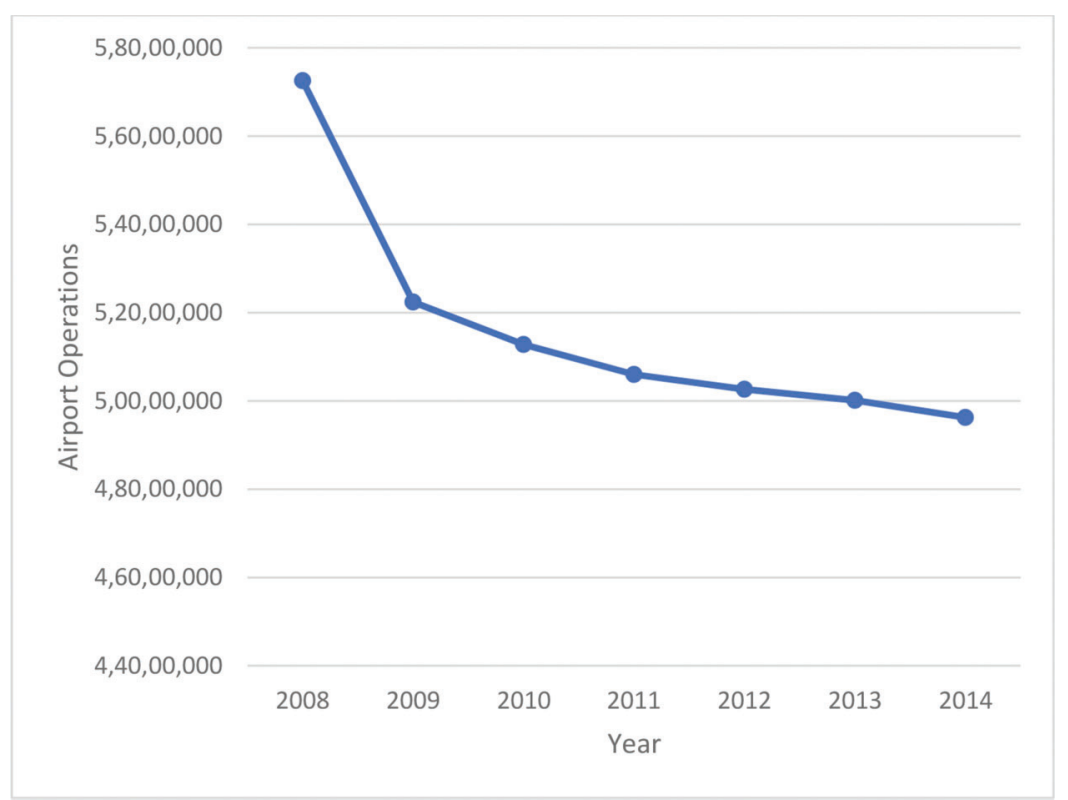

Figure 7. Excel graph of airport operations volumes 2008-2014. From FAA (n.d.).

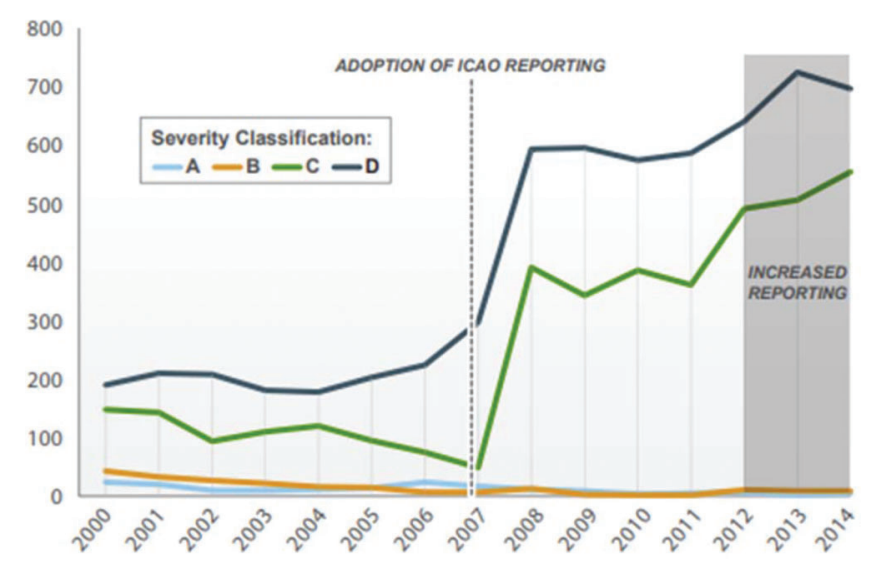

Figure 8. Counts of incursions by severity classification 2000-2014. From FAA (2015b).

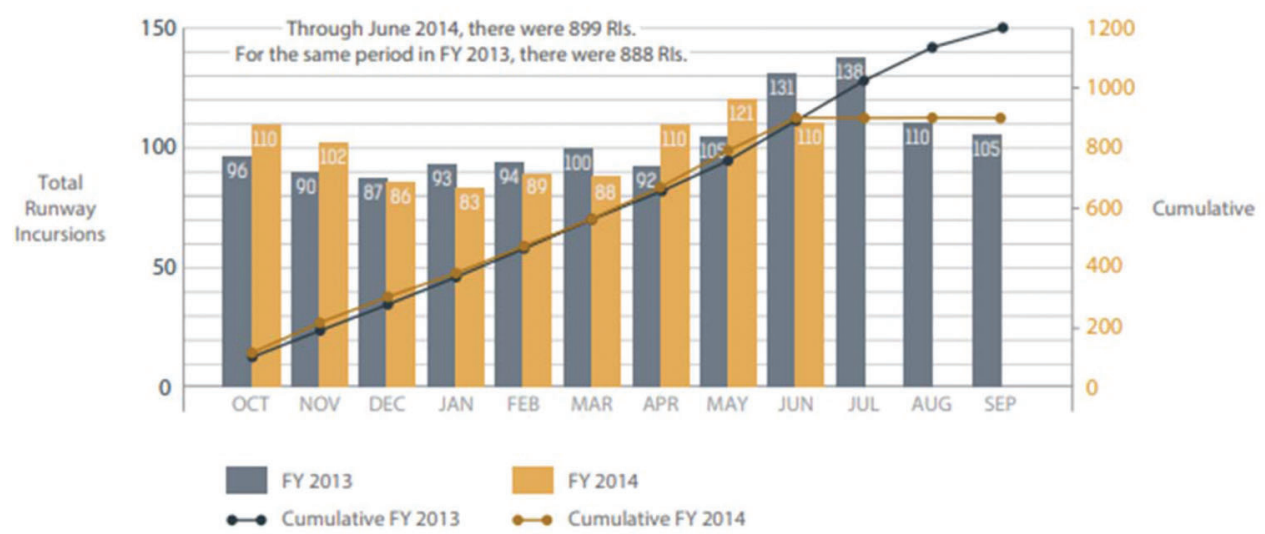

Figure 9. Total monthly and cumulative runway incursions for 2013 and 2014. From FAA (2015c). 


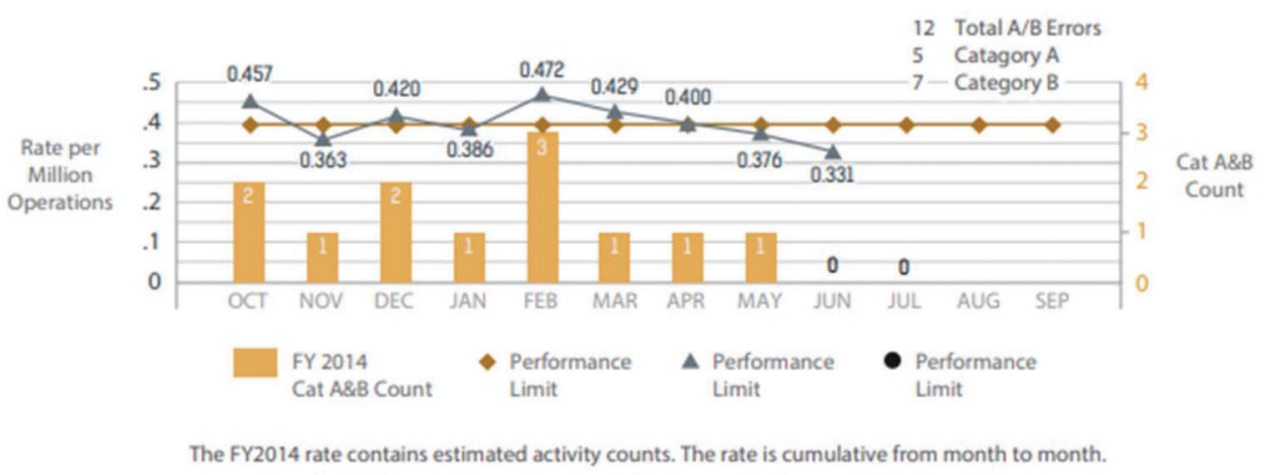

Figure 10. Counts and rates of incursions by month for 2014. From FAA (2015c).

Table 1

Summary of inconsistencies about runway incursion trends within the literature.

\begin{tabular}{ll}
\hline Source & Reported trend \\
\hline Green (2013) & Increase \\
Mrazova (2014) & Decrease (but likely to increase) \\
FAA (2015a, b) & Decrease (some data indicated increase) \\
FAA (2016) & Decrease (some data indicated increase) \\
FAA (2017a) & Decrease (some data indicated increase) \\
FSF (2017) & Both decrease and increase \\
\hline
\end{tabular}

(as noted by the line demarcated by triangles) (see Figure 10) (FAA, 2015b, 2015c).

As can be seen from the available data and research, there is inconsistency among sources about the actual trends in runway incursions. Table 1 summarizes these contradictions. It is essential to consider the context of each data point and graphical display. The FAA presents a moving snapshot of six years in its performance and accountability reports. These irregularities prevent readers from seeing longer-range trends in the data. The use of graphics with conflicting messages (e.g., a sizeable down arrow with data-point lines showing the opposite trend) and the intermixing of incursion rates with counts can be misunderstood by readers. Unfortunately, the FAA does not make the process of calculating its targets known in its publications. One would assume that this is derived from the modeling incursion rates and counts, but it is unclear how the target is derived and why or when it should be adjusted. The mixed messages in FAA documents, media, and within existing research create the potential for confusion in attempts to identify the actual state of runway safety in the USA (FAA 2015b, 2015c, 2017a, 2017b, n.d.; FSF, 2017).

\section{Method}

The purpose of this quantitative, causal-comparative, and correlational study was to analyze empirical data on runway incursions to determine actual differences and trends over time. The goal of the study was to provide insight into whether runway incursions have been decreasing and the potential impacts of FAA safety improvement investments on runway incursions.

\section{Sampling procedures}

All data were garnered from the Operations Network (OPSNET) and Runway Incursions (RWS) FAA databases (FAA, 2017b, n.d.). System-wide airport tower operations volume data were harvested from OPSNET. Overflight traffic was omitted to mimic the method that the FAA uses to calculate rates of incursions. From the RWS database, counts of runway incursions were collected by severity type (i.e., A, B, C, and D). Rates of incursion occurrence were calculated for each year by dividing the total number of incursions for each severity type, by the applicable total airport tower volume for the year. Data were selected from 2001 through 2017 as RWS only provides data back to 2001 and, at the time of the study, 2018 data were incomplete.

\section{Sample size, power, and precision}

Sample sizes were limited by the eighteen years of data that were available. A priori power calculations were conducted for the statistical analyses. It should be noted that more data than were available would be necessary to ensure 0.80 power. Post hoc power analysis is discussed in the results.

\section{Measures}

Count data from OPSNET were collected and reflect the total number of non-overflight towered airport operations. Count data from RWS were collected and reflect the number of runway incursions by type of severity. Data from both sources were downloaded in comma-separated values (CSV) file format for use with statistical software. Generally, government data are considered to be of high validity and reliability due to mandatory reporting and administrative oversight. Annual rates of incursions were calculated using Microsoft Excel to divide the number of incursions by the total tower airport operations for each 
year. All rates were calculated on a PMO basis, which is the typical value used by the FAA. Because of the nature of counts and the distributions of the data, non-parametric tests were utilized for analysis of these types of data (Field, 2013). SPSS statistical software was utilized to conduct correlations. SPSS was also utilized to conduct MannWhitney $U$ comparisons of 2001-2007 versus 2008-2017 (last ten years of data) and 2001-2012 versus 2013-2017 (last five years of data). Microsoft Excel and SPSS were used to produce a graphical output of appropriate data.

\section{Research design}

The designs used in this study were causal-comparative and correlational. Mann-Whitney $U$ tests were utilized to determine differences in rates due to the non-parametric nature of the data. Spearman correlations were conducted to evaluate the relationship between incursion rates over time. Spearman correlation was selected due to the discrete nature of years and operations (Field, 2013; Salkind, 2010; University of Minnesota Library, 2018). The decision to use this type of analysis as well as its applicability for assessing trends over time were adapted from Ogihara et al. (2015). Because both comparison and relationships within the data were being evaluated, these two designs were found to be appropriate to guide this study (Creswell \& Creswell, 2017).

\section{Results}

\section{Statistical and data analysis}

\section{Incursions: General trends and differences}

SPSS was utilized to produce descriptive statistics on the data. A summary of the descriptive values can be found in Table 2. Incursions were grouped by severity as A and B as well as $\mathrm{C}$ and $\mathrm{D}$, to ensure appreciable scales. Spearman correlations were calculated in SPSS to assess the relationship of the year with rates of runway incursions by type of severity. The output of this calculation can be found in

Table 2

Descriptive statistics: operations, $A, A$ rate, $B, B$ rate, $C, C$ rate, $D$, and $D$ rate.

\begin{tabular}{lcccc}
\hline Variable & Mean & StDev & Variance & Median \\
\hline Ops & $56,040,790$ & $6,320,606$ & $3.99501 \times 10^{13}$ & $52,239,072$ \\
A & 9.29 & 5.70 & 32.47 & 8.00 \\
A_Rate & 0.01626 & 0.00898 & 0.00008 & 0.01581 \\
B & 9.53 & 5.84 & 34.14 & 9.00 \\
B_Rate & 0.01649 & 0.00893 & 0.00008 & 0.01528 \\
C & 352.8 & 246.7 & 60865.8 & 365.0 \\
C_Rate & 0.678 & 0.509 & 0.259 & 0.667 \\
D & 1234 & 628 & 393,840 & 1197 \\
D_Rate & 2.323 & 1.325 & 1.755 & 2.091 \\
\hline
\end{tabular}

Note. A, B, C, and D are counts. Incursion rates are noted as "rate."
Table 3

Spearman correlations: year, A rate, $B$ rate, $C$ rate, and $D$ rate.

\begin{tabular}{lcrrr}
\hline & Year & A rate & B rate & C rate \\
\hline A rate & -0.206 & & & \\
& 0.428 & & & \\
B rate & -0.461 & 0.123 & & \\
& 0.063 & 0.639 & & \\
C rate & 0.931 & -0.365 & -0.331 & \\
& $0.000^{* *}$ & 0.149 & 0.195 & \\
D rate & 0.995 & -0.216 & -0.434 & 0.936 \\
& $0.000^{* *}$ & 0.406 & 0.082 & $0.000^{* *}$ \\
\hline
\end{tabular}

Note. Incursion rates are noted as "rate." Top number in each cell is Spearman $\rho$, below is $p$-value.

$* * p<0.01$.

Table 4

Bootstrapping BCa confidence intervals $(C I)$ : year, A rate, $B$ rate, $C$ rate, $D$ rate, and total rate.

\begin{tabular}{|c|c|c|}
\hline \multirow[t]{2}{*}{ Rate type } & \multicolumn{2}{|c|}{ Year } \\
\hline & Lower CI & Upper CI \\
\hline A rate ${ }^{\mathrm{a}}$ & -0.676 & +0.360 \\
\hline $\mathrm{B}$ rate $^{\mathrm{a}}$ & -0.860 & +0.126 \\
\hline $\mathrm{C}$ rate & +0.800 & +0.978 \\
\hline $\mathrm{D}$ rate & +0.962 & +1.00 \\
\hline Total rate & +0.013 & +0.0963 \\
\hline
\end{tabular}

${ }^{\mathrm{a}} \mathrm{CI}$ crosses zero.

Table 3. For this study, correlation coefficient values are considered to be weak when less than 0.30 , moderate when 0.30-0.699, and strong when greater than 0.70 (Field, 2013). According to several statistical theorists, Bonferroni corrections in correlation analysis are considered unnecessary, and therefore they were not applied (Field, 2013; Perneger, 1998). Correlation was used in lieu of regression because of the inapplicability of parametric analysis. To further guard against issues of distributions of the data, correlation calculations included bootstrapping 95\% confidence intervals utilizing bias-corrected accelerated (BCa) methods (Field, 2013).

Spearman's $\rho$ correlations with ascending years from 2001 to 2017 indicated that a weak negative relationship existed with the rate of A severity events while a moderate negative relationship existed with rates of B severity incursions $(p>0.05)$. Strong, positive correlations were noted with $\mathrm{C}$ and $\mathrm{D}$ severity rates of incursions $(p<0.001)$. The relationship between ascending year and total incursion rates (including all severity types) was significant ( $\rho=0.995$, $p<0.001$ ). Bootstrapped BCa confidence intervals for each rate are provided in Table 4.

Evaluating correlations of counts utilizing Spearman's $\rho$, there was a significant, strong negative association between total tower airport operations and ascending years (see Table 5). There was a moderate negative correlation between ascending years and counts of A and B severity incursions. Contrarily, C and D counts were strongly, 
Table 5

Spearman correlations: year, operations, $A, B, C$, and $D$.

\begin{tabular}{lccccc}
\hline & Year & Operations & $\mathbf{A}$ & $\mathbf{B}$ & $\mathbf{C}$ \\
\hline Operations & -0.924 & & & & \\
& $0.000^{* *}$ & & & & \\
$\mathrm{~A}$ & -0.313 & 0.321 & & & \\
& 0.222 & 0.209 & & & \\
$\mathrm{~B}$ & -0.617 & 0.522 & 0.308 & & \\
& $0.008^{*}$ & $0.032^{*}$ & 0.229 & & \\
$\mathrm{C}$ & 0.926 & -0.860 & -0.447 & -0.487 & \\
& $0.000^{* *}$ & $0.000^{* *}$ & 0.072 & $0.047^{*}$ & \\
$\mathrm{D}$ & 0.990 & -0.922 & -0.313 & -0.581 & 0.929 \\
& $0.000^{* *}$ & $0.000^{* *}$ & 0.222 & $0.015^{*}$ & $0.000^{* *}$ \\
\hline
\end{tabular}

Note. A, B, C, and D are counts. Top number in each cell is Spearman's $\rho$, below is $p$-value.

$* p<0.05 ; * * p<0.01$. positively correlated to years. A and B counts were weakly and negatively correlated with $\mathrm{C}$ and D counts. Thankfully, $\mathrm{C}$ and $\mathrm{D}$ events are negatively correlated with $\mathrm{A}$ and $\mathrm{B}$ events, so the rise of the former will not, in theory, necessarily eventually result in increases of the latter. Assessing $\mathrm{C}$ and $\mathrm{D}$ counts showed a strong, positive association between specific groups of these events. There did not appear to be an association between total tower airport operations and total incursion counts $(\rho=-0.086$, $p=0.743)$.

In order to further gauge the directionality of data, trendlines were added to visualizations of incursion counts and rates using the linear trendline function of Excel (see Figures $11-14) . R^{2}$ values calculated by the Excel trendline function are included for rates. Rates for the last five and

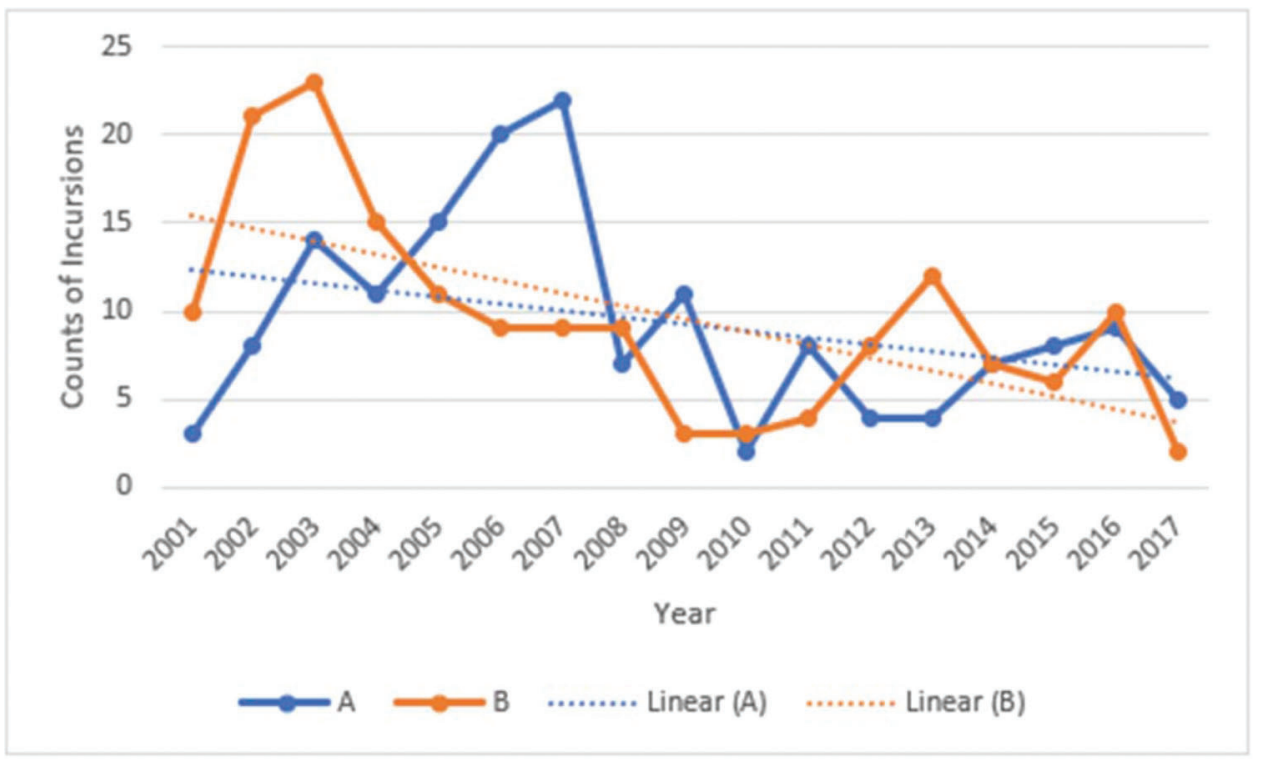

Figure 11. A and B severity counts of incursions 2001-2017 with linear trendlines.

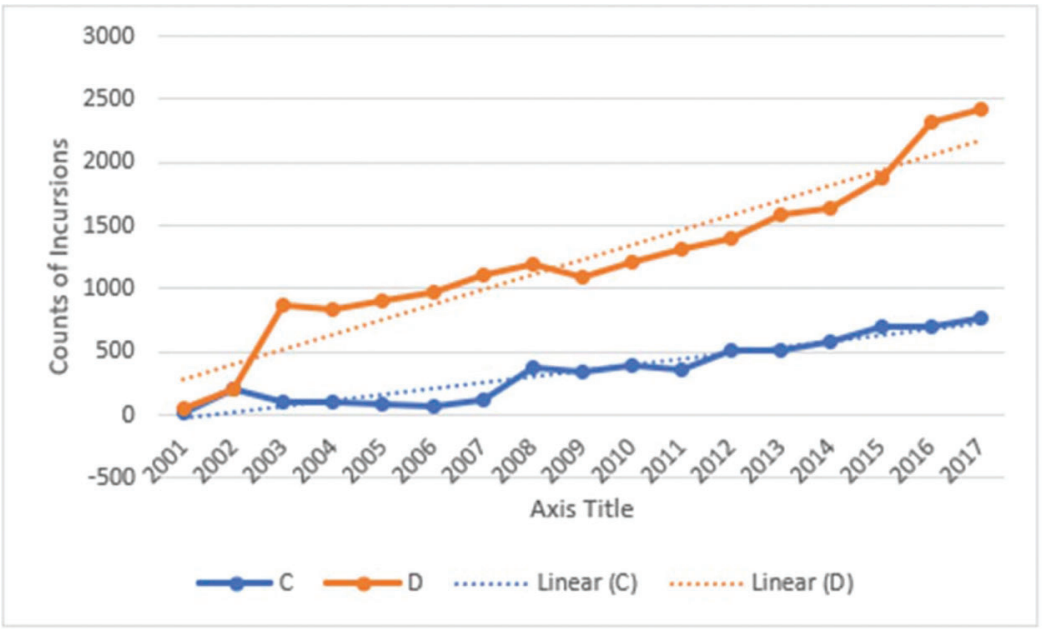

Figure 12. C and D severity counts of incursions 2001-2017 with linear trendlines. 


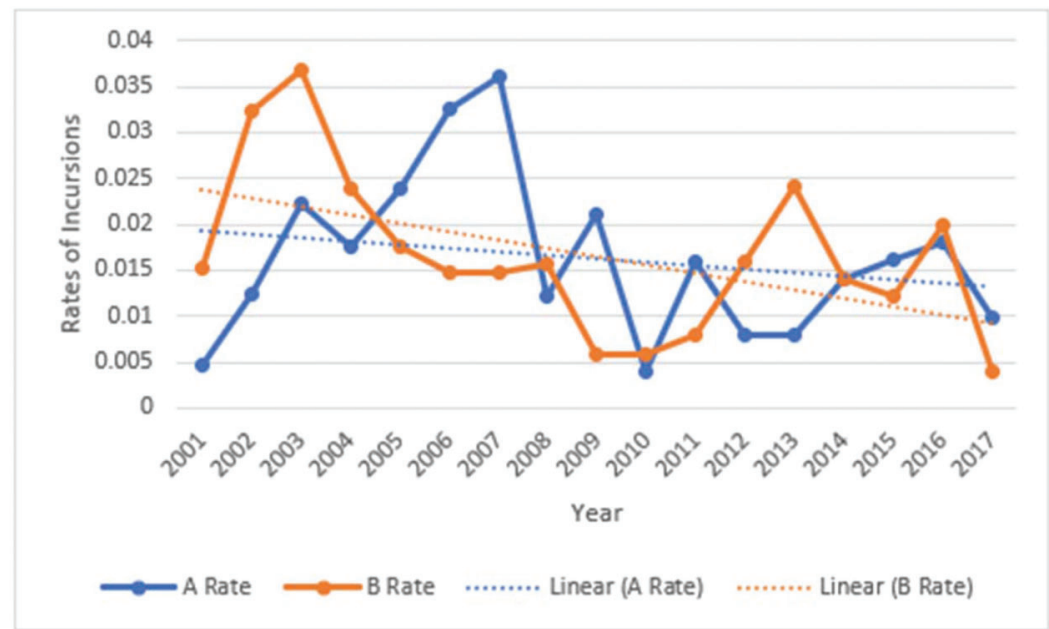

Figure 13. A and B severity rates of incursions $2001-2017$ with linear trendlines. $\left(R^{2} \mathrm{~A}\right.$ rate $=0.0481$; $\mathrm{B}$ rate $=0.2598$. $)$

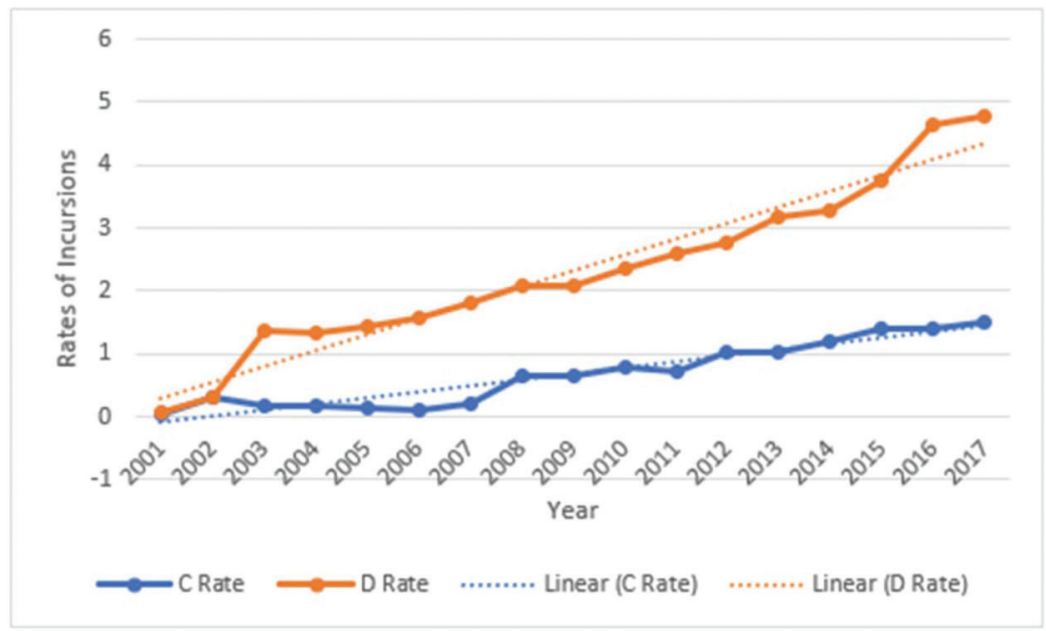

Figure 14. $C$ and D severity rates of incursions $2001-2017$ with linear trendlines. $\left(R^{2} \mathrm{C}\right.$ rate $=0.9118$; B rate $=0.9502$.

Table 6

Mann-Whitney $U$ tests for $A, B, C$, and $D$ rates.

\begin{tabular}{lcccc}
\hline Years & A rate $\boldsymbol{U}, \boldsymbol{r}$, and $\boldsymbol{p}$-value & B rate $\boldsymbol{U}, \boldsymbol{r}$, and $\boldsymbol{p}$-value & $\mathrm{C}$ rate $\boldsymbol{U}, \boldsymbol{r}$, and $\boldsymbol{p}$-value & $\mathrm{D}$ rate $\boldsymbol{U}, \boldsymbol{r}$, and $\boldsymbol{p}$-value \\
\hline $2001-2007$ vs. $2008-2017$ & $16.0,0.449,0.064$ & $15.0,0.473,0.051$ & $0,0.828,0.001^{*}$ & $0,0.828,0.001^{*}$ \\
$2001-2012$ vs. 2013-2017 & $24.0,0.153,0.527$ & $25.0,0.128,0.598$ & $0,0.766,0.002^{*}$ & $0,0.766,0.002^{*}$ \\
\hline
\end{tabular}

Note. Parameter $r$ is effect size.

*Significance with Bonferroni correction.

ten years were compared to periods previous there of (2001-2012 vs. 2013-2017 and 2001-2007 vs. 20082017, respectively) using Mann-Whitney $U$ tests. The results are displayed in Table 6. Linear trendlines were added to visualizations of incursion counts and rates using the trendline function of Excel for further clarity of actual data trends (see Figures 11-14) (FAA, 2016, 2017a).

Incursions: Post hoc power analysis

Post hoc power analysis was conducted on insignificant correlations and Mann-Whitney $U$ tests, which were found not to meet the desired threshold of $1-\beta=0.80$. Unfortunately, due to the type of data being analyzed, it was not possible to increase sample sizes. These issues are discussed in the limitations section of the discussion.

\section{Discussion}

For simplicity purposes, the discussion of findings will follow the order of tables and other outlined statistical results then move on to figures. 
Results in tables and non-graphical format

Regarding the trend in runway incursions over the long term, i.e., from 2001 through 2017, there was a significant and strong, positive correlation between incursion rates and ascending years. In short, incursion rates, as a whole, have increased over time. Dissecting each severity category in Table 3, it is evident that category $\mathrm{C}$ and $\mathrm{D}$ incursion rates have been increasing over time and are the primary reason why the overall rate has also been increasing. Rates for category A and B incursions do appear to decrease over time, though weakly for A events and moderately for B events. Regardless of these findings, neither correlations for A nor B were significant, although this can arguably be irrelevant due to the nature of correlation as an effect size and differing opinions among statisticians on the importance of significance in correlational analysis. More evidence, however, on the lack of change in A and B incursion rates can be garnered from the bootstrapped $\mathrm{BCa}$ confidence intervals (Table 4), which, for these two types of severity, included zero.

When examining counts of incursion relationship with the passage of years, categories A and B were negatively correlated, while C and D were positively correlated, as to be expected based on rate data. Correlation results indicate that A events were weakly associated with ascending years while B events were moderately so. C and D counts, just as was the case with rates, were strongly associated (see Table 5). The relationships between incursion counts and the number of operations show results contrary to assumptions found in the literature. As seen in Table 5 data, there was a significant, strong negative correlation between operations over time, thus indicating overall decreased operational volumes from 2001 to 2017. The relationships between incursion category and traffic volume do not seem to entirely agree with assumptions within the literature that incursion incidence is tied to operational measurements. Categories A and B were moderately positively correlated ( $\rho=0.321$ and $\rho=$ 0.522 , respectively) with this decrease in traffic, yet for $\mathrm{C}$ and $\mathrm{D}$, there was a more logical strong, negative correlation ( $\rho=-0.860$ and $\rho=-0.922$, respectively).

Mann-Whitney $U$ test results comparing rates for specific data ranges and each severity category of incursion are displayed in Table 6. When comparing 2001-2007 rates to the most recent ten years of data (2008-2017), there were no significant differences for category A and B events while there were significant differences between $\mathrm{C}$ and $\mathrm{D}$ results. The same pattern was true for the comparison of 2001-2012 with the most recent five years of rate data (2013-2017).

\section{Results displayed in figures}

Long-term (2001-2017) graphics of A and B severity counts and rates across the USA show a rather erratic pattern of occurrences (Figure 11). For categories C and D
(Figure 12), the trend is more intuitive. Due to the distribution characteristics of rates (i.e., fitting the constraint of normality), $R^{2}$ values were included from the underlying regression calculation provided by the graphical options of Microsoft Excel (Figures 13 and 14). Not surprisingly, $R^{2}$ for A incursion rates indicated a large amount of variance $\left(R^{2}=0.0481\right)$ from the trendline, and the trendline for B incursion rates also indicated a poor fit $\left(R^{2}=0.2598\right)$ albeit better than that for category A. For rates of $\mathrm{C}$ and $\mathrm{D}, R^{2}$ showed close fits with the trendlines $\left(\mathrm{C} R^{2}=0.9118 ; \mathrm{D} R^{2}=0.9502\right)$.

These findings shed light on the confusing nature of how the FAA often reports its data. Depending upon the timeframe selected, the argument about whether incursion counts are changing could be answered differently. Moreover, if one is examining trends utilizing a regression line, the answer may be different from examining 2001 counts with those in 2017. As FAA reports often only provide snapshots of data from the most recent five years, actual differences and trends over longer-term periods may be overlooked. Interestingly, if using the philosophy found in several reports presented by the FAA-directly connecting a line between the counts or rates from the beginning of a reporting period to the end-the following conclusions could be presented: from 2001 to 2017, both rates and counts of category A, C, and D incursions have increased while category B was the only group to decrease. Also, if incursions were decreasing, it would be assumed that a reduction in target rates would be applicable, such as when the FAA adjusted its target from 0.450 PMO to 0.395 PMO in 2012. The target has been kept at 0.395 PMO through 2017 .

\section{Limitations}

The study does have some limitations that must be identified. One limitation is that the FAA changed the definition of runway incursions during data reporting periods. Also, it is not readily apparent if or how reporting measures changed during the periods studied in existing research and within the current study. Another limitation of this study is related to the power of certain aspects of the statistical analysis. Non-significant findings in tests with small samples cannot assuredly denote the lack of a difference or effect. Thus, it cannot be said with certainty that insignificant findings in this study were the result of the lack of an actual effect or the inability of the test to detect such an effect. The only means of increasing power would have been to increase sample sizes, which was impossible considering the nature of the data and the limited availability of data from the periods analyzed.

\section{Delimitations}

This study was delimited to include only runway incursions in the USA due to the accessibility of the data. 
Only data from FAA sources were utilized as they were assumed to provide the most accurate and comprehensive incursion occurrence information. Spearman correlations of counts and rates with the passage of time (ascending years) were selected as a means of assessing changes over time, as exemplified within the literature. Confirmatory analysis of identified trends was attempted through other analyses, i.e., Mann-Whitney $U$ tests.

\section{Conclusion}

In summary, the numbers and rates of runway incursions have been increasing since 2001. Some of this can be attributed to the change in the definition of incursions, though in particular C and D severity incursions have steadily increased even after this event. The steady increase in these categories has been attributed, in part, to increased reporting. However, one would assume a drastic increase in the years immediately following inclinations for increased reporting followed by trends that would follow traffic volumes, at least to some extent. This is not the case, as evident from the data. The number of $\mathrm{A}$ and $\mathrm{B}$ incursions have had a downward trend since 2001. Graphical data also concur with these findings. For category B incursions, only 2016-2017 saw significant differences from expected. Year over year increases in category $\mathrm{C}$ and $\mathrm{D}$ events were evident in the analyses and graphical data. Further assessment of variations or lack thereof was confirmed through the Mann-Whitney $U$ tests utilized to compare periods (20012007 vs. 2008-2017 and 2001-2012 vs. 2013-2017) showing that there were no significant differences for category A and B while there were significant differences indicated for categories $\mathrm{C}$ and $\mathrm{D}$.

It is hoped that the findings of this study will provide aviation stakeholders with more detailed data, analysis, and interpretation of runway incursion incidence. Expectantly, the FAA should make a more concerted effort to precisely and analytically report incursion data made to the public. It is reasonable to expect that the FAA display longer-range data trends and to include standard measures of trend in graphical depictions. For example, regression trendlines or simple moving averages are a more reasonable means of displaying change. In particular, moving averages are intuitive and more responsive to annual changes in the data. Congressional oversight of investments requested by the FAA should include an examination of available data which should be confirmed with sources of such data.

\section{Suggestions for Future Research}

Through the conduct of this study, needs for further inquiry into runway incursions were identified. These include:

- Yearly analysis and reporting to monitor and report on trends in runway incursions.
- Investigate the culture of reporting runway incursions. This should include percentages of incursions that are reported, factors that affect reporting, and how this has changed over time.

\section{References}

Creswell, J. W., \& Creswell, J. D. (2017). Research design: Qualitative, quantitative, and mixed methods approaches. Thousand Oaks, CA: Sage Publications.

FAA. (2007). FAA needs to improve ASDE-X management controls to address cost growth, schedule delays, and safety risks. Retrieved from https://www.oig.dot.gov/sites/default/files/WEB_ASDE-X_10-31-07. pdf

FAA. (2008). Runway safety report: June 2008. Retrieved from https://www.faa.gov/airports/runway_safety/publications/media/pdf/ RSReport08.pdf

FAA. (2009). Annual runway safety report: 2009. Retrieved from https:// www.faa.gov/airports/runway_safety/publications/media/Annual_ Runway_Safety_Report_2009.pdf

FAA. (2010). Annual runway safety report: 2010. Retrieved from https:// www.faa.gov/airports/runway_safety/publications/media/Annual_ Runway_Safety_Report_2010.pdf

FAA. (2014). FAA performance and accountability report. Retrieved from https://www.faa.gov/about/plans_reports/media/2014_FAA_PAR.pdf

FAA. (2015a). FAA performance and accountability report. Retrieved from https://www.faa.gov/about/plans_reports/media/2015_FAA_ PAR.pdf

FAA. (2015b). National runway safety report 2013-2014. Retrieved from https://www.faa.gov/airports/runway_safety/publications/media/ Runway-Safety-Report-2013-14.pdf

FAA. (2015c). National runway safety plan 2015-2017. Retrieved from https://www.faa.gov/airports/runway_safety/publications/media/2015_ ATO_Safety_National_Runway_Safety_Plan.pdf

FAA. (2016). FAA performance and accountability report. Retrieved from https://www.faa.gov/about/plans_reports/media/2016_FAA_PAR.pdf

FAA. (2017a). FAA performance and accountability report. Retrieved from https://www.faa.gov/about/plans_reports/media/2017_FAA_ PAR.pdf

FAA. (2017b). Runway Incursion Database (RWS): Database query tool. Retrieved from https://catalog.data.gov/dataset/runway-incursiondatabase-rws-data-query-tool-a27d7

FAA. (n.d.). The Operations Network (OPSNET). Retrieved from https:// aspm.faa.gov/opsnet/sys/Main.asp

Field, A. (2013). Discovering statistics using IBM SPSS statistics. Thousand Oaks, CA: Sage.

FSF. (2017). Serious runway incursions down at U.S. airports. Retrieved from https://flightsafety.org/runway-incursions-down/

Green, L. L. (2013). Analysis of runway incursion data. In 2013 Aviation Technology, Integration, and Operations Conference (p. 4400).

Morrison, S. A., \& Winston, C. (2008). The effect of FAA expenditures on air travel delays. Journal of Urban Economics, 63(2), 669-678.

Mrazova, M. (2014). Runway incursions-clear and constant danger. Incas Bulletin, 6(3), 71-80.

Mutzabaugh, B. (2015). Emirates pushes A380 seating capacity past 600. Retrieved from https://www.usatoday.com/story/todayinthesky/2015/ 04/16/emirates-pushes-a380-seating-capacity-past-600/25771747/

NTSB. (n.d.). Most wanted. Retrieved from https://www.ntsb.gov/news/ events/Pages/196.aspx

NTSB. (2007). Airport runway accidents, serious incidents, recommendations, and statistics. Retrieved from http://www3.alpa.org/portals/alpa/ runwaysafety/NTSBRunwaySafetyfactsheet.pdf

Ogihara, Y., Fujita, H., Tominaga, H., Ishigaki, S., Kashimoto, T., Takahashi, A., ... Uchida, Y. (2015). Are common names becoming 
less common? The rise in uniqueness and individualism in Japan Frontiers in psychology, 6, 1490.

OIG. (2018). FAA faces challenges in implementing and measuring the effectiveness of its 2015 runway safety Call to Action initiatives. Retrieved from https://www.oig.dot.gov/sites/default/files/FAA\%20 Runway\%20Safety\%20Initiatives\%5E6-27-18.pdf

Perneger, T. V. (1998). What's wrong with Bonferroni adjustments? BMJ, 316(7139), 1236-1238.

Salkind, N. J. (Ed.). (2010). Encyclopedia of research design (Vol. 1). Thousand Oaks, CA: Sage.

Schönefeld, J., \& Möller, D. P. F. (2012). Runway incursion prevention systems: A review of runway incursion avoidance and alerting system approaches. Progress in Aerospace Sciences, 51, 31-49.
United States Government Accountability Office. (2008). Testimony before the Subcommittee on Aviation, Committee on Transportation and Infrastructure, House of Representatives: Aviation safety-FAA has increased efforts to address runway incursions. Retrieved from https://www.faa.gov/airports/runway_safety/publications/media/ GAO\%20Report\%20on\%20Runway\%20Safety\%20Sept.\%202008.pdf

University of Minnesota Library. (2018). 7.2 Correlational research. Retrieved from https://open.lib.umn.edu/psychologyresearchmethods/ chapter/7-2-correlational-research/

Van Eekeren, R., Wright, S., \& Čokorilo, O. (2018). Early cost safety analysis of runway events. International Journal for Traffic \& Transport Engineering, 8(3), 261-270. 